\title{
Integrating Model of Resilience, Engagement, and Motivation
}

\author{
Alison Jolliff ${ }^{1}$ and David Strubler ${ }^{2}$ \\ ${ }^{1}$ Learning \& Development Specialist, Oakland University, Michigan, USA \\ ${ }^{2}$ Department of Organizational Leadership, School of Education and Human Service, Oakland University, Michigan, USA \\ *Correspondence: David Strubler, strubler@oakland.edu
}

\begin{abstract}
Over the past 70 years, resilience, engagement, and motivation (REM) studies have largely developed as independent theoretical and research disciplines. Yet, in conducting a thorough literature review of these three work-related fields, we discovered that they share some identical or similar concepts, e.g., self-efficacy. We also discovered that concepts from these three fields of study could be integrated into a more comprehensive research model. That model can then be used to provide a prescription to help managers improve their employees' and their organizations' outcomes of performance, productivity, quality, etc.

Therefore, we provide an analytical review of these theories and research findings as they psychologically impact employees in work environments. We synthesize the growing knowledge regarding the primary factors influencing REM and provide eight useful REM research propositions to inform the model. The model features antecedents to resilience, engagement, and motivation. From this work, we posit that an integrated, practical model will be needed to improve employee involvement and performance that ultimately impacts organizational performance.

Therefore, we focus primarily on those REM psychological characteristics of organizational members as they relate to antecedent concepts and conditions. A critique of the state of the REM literature is provided and targeted suggestions are outlined to guide future empirical and theoretical work in a meaningful direction.
\end{abstract}

Keywords: Resilience, Engagement, Motivation

\section{ARTICLE INFORMATION}

Author(s): Alison Jolliff and David Strubler

Received: 20 Feb, 2021; Accepted: 28 April, 2021; Published: 01 June, 2021; e-ISSN: 2347-4696;

Paper Id: BMN-IJBMR-2021-31;

Citation: doi.org/10.37391/IJBMR.090208

Webpage-link:

https://ijbmr.forexjournal.co.in/archive/volume-9/ijbmr-090208.html

\section{INTRODUCTION}

The outcome of this literature review is an initial model based on the analysis, integration, and synthesis of three significant concepts: resilience, engagement and motivation (REM). We review the literature on the development of each construct before integrating the shared antecedents and commonalities into a model. Several links or overlaps have been found among these three. Firstly, resilience is one of the personal resources that contributes to the variance in engagement [1]. Second, engagement clearly requires motivation [2,3]. Third, selfefficacy and self-control are two important factors that support and encourage motivation $[4,5]$ and these form a part of resilience. In our research, we found no other proposition that attempts to analyze the interconnections to form a holistic model such as REM.

Our research found lack of agreement regarding the definitions and boundaries of two of our major constructs - and some of their component parts - as researchers study certain aspects and attempt to clarify and develop the individual concepts. There has been debate regarding the impact one component may have on another, such as the long-standing discussion between social-cognitive theorists $[4,6-8]$ and perceptual control theorists $[9,10]$. Before suggesting how various aspects may interrelate, we discuss the development of each main dimension in REM, together with their commonalities. We now consider the lack of clarity regarding resilience, our first main construct, detailing its development from origins in clinical psychology forty years ago.

\section{RESILIENCE}

Resilience was initially investigated after the second World War, with regard to major traumas experienced during that tumultuous period. Here, being resilient meant survival in the face of great and wide-ranging adversity, over a period of several years. Kobasa [11] focused on the aspect of hardiness, looking at the survivor mentality produced by envisaging each change as a challenge or opportunity, by committing to the response, and using self-control to see it through. Later work by Rutter [12] noted other characteristics of resilient people and suggested that resilience was a dynamic construct that could be learned in response to adversity - stress could have a strengthening effect - and that previous successes were another factor that would increase the level of resilience.

Meanwhile, towards the turn of the century, moving away from the focus on mental health into "positive psychology", research was broadened to include segments of the normal population. Consequently, the model was expanded to include more everyday adversity and stress, with coping skills being added to the survival constituent to allow thriving after 
difficulties, or even post traumatic growth $[13,14]$ rather than simply sustainability. However, several researchers in the area of resilience clung to aspects of earlier conceptualizations from the field of clinical psychiatry, while providing a perspective from positive psychology. For example, we have psychological capital (PsyCap) [15], with its four factors of resilience, hope, optimism, and self-efficacy. The definitions of hope and resilience, in this case, are taken from Snyder's [16] viewpoint based in clinical work with major trauma, where "resilience" means survival and personal goals are based on "hope" for the future.

A recent overview by Seligman [17] noted that resilience follows a normal distribution, with most people having a level of resilience within a standard range. He also stated that resilience is an interaction among intrapersonal, interpersonal, and social dynamics. Seligman concluded that if resilience is not currently evident, testing and training can help individuals prepare for stressors that inevitably occur. The potential to build resilience is necessary for military personnel and was successfully put into practice $[18,19]$. This idea of resilience as a dynamic process, which can fluctuate over time and context but can also be taught and increased, is gradually replacing the original trait conception. This notion has created a greater need for resilience measurements, especially in the world of work, and over recent decades researchers have modelled and developed scales to measure this.

\subsection{Instruments that Measure Resilience}

In a detailed review of available instruments, Rees, et al. [20] agreed with Windle, et al. [21] that there was still no standard psychological measure for resilience. From the several hundred measures investigated, the Connor-Davidson Resilience Scale [22] is one of the more commonly used examples that Rees, et al. [20] considered. As with many scales, it includes a range of self-report items drawn from resilient individuals. These have been used to test the scale with diverse samples, from the standard population with normal stress levels through to the clinical range (e.g., those suffering from minor anxiety up to PTSD). This scale measures responses from subjects regarding the last month, and as self-report it is limited in terms of external or objective assessment.

Further instruments continue to be created. McLarnon and Rothstein [23] developed the Workplace Resilience Inventory using the model for resiliency at work proposed by King and Rothstein. This inventory includes questions measuring current expected response to any immediate adversity and items regarding dynamic self-regulation; also, several looking at more stable constructs such as beliefs and values.

However, there is still confusion about exactly what resilience entails, the components it might include, and the boundaries between these various constructs. Indeed, Geers, et al. [24] pointed out that there may even have been some overlap among their own constructs of hope, self-mastery and optimism. Hence, several questions regarding resilience remain disputed. Firstly, whether it is defined from a clinical perspective or whether - for the everyday or work context - it focuses more on self-monitoring or self-regulation towards achievable goals. Secondly, whether it fluctuates as a stateRutter's [12] early conceptualization of resilience as dynamic and trainable has continued to be supported by several researchers through to Seligman's [17] overview. However, others still cling to the concept of trait resilience or see it as an outcome (for comparisons, see the review by Happer, et al. [25]).Meanwhile, there seems to be one defining phrase for resiliency agreed by most researchers, and this involves "bouncing back from adversity or challenge," [15, 26]. Consequently:

Proposition 1: Resilience in the normal population is defined as the ability to bounce back from adversity or challenge toward achievable goals. It is a dynamic state, a trainable response to adversity.

The rest of the discussion over resilience and its components continues. There has been similar debate about our second main dimension, engagement.

\section{ENGAGEMENT THEORIES AND MODELS}

Several models have been suggested to explain engagement since Kahn's [2] original proposal but there is currently no universal definition. Kahn's pioneering work suggested that engagement occurs when a person is involved at work with a positive affective response to a given task.

\subsection{Kahn's Proposal [2]}

For Kahn, personal engagement was the "simultaneous employment and expression of a person's 'preferred self' in task behaviors that promote connections to work and to others; personal presence (physical, cognitive and emotional), and active, full role performances" (p. 700). Conversely, Kahn described disengagement as "withdrawal and defense of a person's preferred self, lack of connections; physical, cognitive and emotional absence; passive, incomplete role performances" (p. 701). He further talked about removing personal input from physical, cognitive and emotional work with the following results: "robotic' or automatic behaviors, burned out, disinterested or uninvolved, or with lack of effort" (p. 701). Kahn described three psychological conditions that affect how much people bring to their role. "Meaningfulness" is the first condition and requires an obvious reason for the task with some sort of personal end-goal or satisfaction of a personal need. Extrinsic motivation such as pecuniary reward is not, of itself, enough to promote full personal presence in a task, although the physical aspects alone may well be invoked. There must be intrinsic motivation, such as learning a new skill, mastering a challenge, or meeting a self-imposed deadline, if the cognitive and emotional inputs are to be maximized. Kahn's second condition, "safety," requires that the employee trusts the work environment-feels no physical threat, such as job loss, either immediate or potential; has social support at work, and no psychological stress or pressure to perform in a certain way. The third condition, "availability" 


\section{Business and Management Research (IJBMR)}

Review Article | Volume 9, Issue 2 | Pages 178-189 | e-ISSN: 2347-4696

refers to the personal energy that the employee brings to the role, and this will depend to some extent on both their personality and current personal situation (the level of their personal resources).

\subsection{Reviews of the Main Approaches}

In reviews of the literature, Shuck and Wollard [27] agreed with Kahn's [2] description that, work engagement comprises a "cognitive, emotional \& behavioral state directed toward desired organizational outcomes", (p.103). However, as well as supporting Kahn's "need satisfying" view [2], Shuck [28] also considered several other approaches to the concept of engagement at work: Burnout-antithesis, using the Maslach Burnout Inventory (MBI), [29]; another conceptualization as satisfaction-engagement [30]; and Saks' [31] multidimensional approach. In other reviews, Simpson [32] and Knight, et al. [33] also investigated the first three of these approaches or constructs. The review by Knight et al. further included the job demands-resources (JD-R) model [1].

\subsection{Burnout and Engagement}

Maslach and Leiter, [34] linked burnout and engagement, suggested that the earlier concept of burnout [29] was the wearing out of engagement, in that engagement included "energy, involvement and efficacy" (p. 24), whereas burnout comprised exhaustion, cynicism and ineffectiveness. Since 1997, researchers in many countries have continued to investigate burnout, its components, symptoms, and mitigating factors across a variety of workplaces. Although agreeing with the definition and an opposing link between engagement and burnout, Schaufeli, et al. [35] operationalized engagement differently from the MBI. They designed The Utrecht Work Engagement Survey (UWES) to measure "vigor, dedication and absorption", which broadly paralleled the "energy, involvement and efficacy” of the MBI (p. 24).

Knight, et al. [33] reported on a meta-analysis by Cole, et al. [36]. Here 50 independent samples had been assessed with the result that burnout and engagement were highly correlated and were similarly associated with correlates. Moreover, the effect size of engagement had been greatly diminished by controlling for burnout. Cole, et al. [36] had concluded that burnout and engagement were likely to be part of the same dimension.

\subsection{Engagement-satisfaction Approach, and Multi-dimensional Format}

The Gallup Organization commissioned a study, where Harter, Schmidt, and Hayes [30] used the construct of job satisfaction as a substitute for other models of engagement. This was an easier concept to explain to employees and to apply in practice throughout a range of industries. Another conceptualization of engagement was the multi-dimensional format explained by Saks [31], where work engagement was split into task, job, or organizational dimensions; engagement was divided into a relatively stable trait level and a more fluid "state" level, which may link to individual tasks. This format re-opened an old debate regarding the difference between state and trait.

\subsection{Engagement and Resources}

To sum, with four models initially, later models linked available resources to engagement, focusing firstly on job resources [1]. A variety of studies linked into their JD-R model which assumed that every occupation had its own specific work characteristics, and these could be classified in two categories as job demands (JD) or job resources (JR). Job demands would drain the mental and physical resources of employees and might lead to burnout (within the energetic process), whereas job resources would aid by improving motivation and engagement, in what Bakker and Demerouti [1] termed the motivational process. These researchers pointed out that, job resources become salient in the face of high job demands. They cited Hobfoll who argued that the prospect of gaining resources acquires its saliency in the context of resource loss, replacement becomes more important. Bakker and Demerouti [1] agreed that by implication job resources became more valuable and gained their motivational potential when employees were confronted with high job demands, and that the processes evoked by job demands and job resources were both concurrent and non-aligned.

In a recent integrating review of the literature, Imperatori [37] further considered the link between job resources and engagement at work. She pointed out that high demands do not necessarily reduce engagement, although they are more likely to coincide with burnout, according to Schaufeli and Bakker [38]. Imperatori [36] suggested that under high demand conditions, work engagement would be best facilitated by increasing job resources. The reasoning given was that studies by Hakanen, et al., and Xanthopoulou, et al. [39] had found reciprocal links between high levels of job resources and high levels of engagement across a time delay. We agree that this will maintain the balance of JD-R without the need to reduce work demands. We further postulate that a high level of job resources has a continued and long-term effect in facilitating engagement in the future, because the employee's perception of that high level does not downgrade unless changes are made. Under high job demand conditions, high job resources are necessary for engagement. Moreover, an earlier challenging success within the same social context would suggest, if anything, an increase in the level of job resources perceived by the successful employee.

Combining personal resources with job resources, Kim, et al. [40] expanded the notion that engagement at work can be explained by work resources, suggesting that personal and work resources in combination were needed. The former would tie in with Kahn's [2] "personal availability", the latter with Kahn's meaningfulness of the task and perceived safety of the work environment, all required for engagement. Personal resources are found in resiliency and these positive personal evaluations create an individual's sense of worth and usefulness [41]. Examples of such resources could be a sense of mastery or self-efficacy, optimism, or self-esteem. Bakker, et al. [42] described several studies where personal resource such as self-efficacy was used to promote goal setting, motivation, and performance. They reported that a 2-year follow-up study [39] replicated and expanded earlier findings: 
Self-efficacy, organizational-based self-esteem, and optimism make a unique contribution to explaining variance in work engagement through time, over and above the impact of job resources and previous levels of engagement. One of these earlier studies, found that a high level of work engagement among female school principals correlated with a high level of personal resources-including resilience, self-efficacy, and optimism-which appeared to have a greater effect on engagement than the remaining personal resources such as social support mechanisms.

In short, engagement is a recent phenomenon, and still being explored as a construct. A recent review by Bakker and Albrecht [43] concluded that the most often used definition was that of Schaufeli, et al. [35]. There is currently a reasonable consensus on the notion that there are two main factors, the energizing and the motivational aspects, with varying terminology for each, and a modicum of accord on the idea that engagement is situation and time specific [44], There is general agreement that work resources are a prerequisite for engagement in the workplace, and acceptance that personal resources play a role too, in determining the level of engagement at a given time. Thus:

Proposition 2: Accepting the definition of engagement from Schaufeli, et al. [35], we agree with its three factors: Vigor, Dedication, and Absorption, with dedication requiring inspiration, challenge and immersion. We propose that within engagement, dedication is an antecedent to vigor, which in turn is an antecedent to absorption.

Proposition 3: Work resources and personal resources are cocurrent antecedents for engagement at work.

There are still many questions to be answered, such as how workforce engagement may be increased; whether absorption is a main factor or simply the result of engagement; and how best to promote engagement in the individual employee. Hence, the construct of engagement is at an early stage of development. By comparison, motivation has been researched for many decades, much more is known about it, and greater levels of agreement exist, although perspectives still show some variation.

\section{MOTIVATION: THEORIES AND MODELS ABOUND}

Our third dimension of REM is motivation. Research into motivation has produced several theories and models, mainly focused in the world of work: They include Expectancy Theory [45, 46], Two-Factor Motivation Theory [47, 48], Goal Setting Theory [49, 50], and Job Characteristics Model [51].

Outside the workplace, motivation has also been explored more generally with established ideas in terms of Social Learning Theory [6] and intrinsic motivation dating back to Koch, [52]. The impact of extrinsic motivation on intrinsic motivation has been studied among several age groups: children, [53, 54]; students [55], and adults. A later metaanalysis confirmed that the addition of extrinsic reward diminished the intrinsic motivation of a task [56]. Deci and Lanzetta [55] used cognitive evaluation theory to conclude that awareness of the reward, together with its contingency and saliency, were particularly important in determining that the intrinsic motivation would be diminished.

The other generalized perspective was provided by Bandura's [6] social learning theory (SLT) which asserts how motivation, behavior, and responses to the environment are all learned through social interaction and modeling. In SLT, self-efficacy precedes outcome expectation, with the belief that an individual can achieve the desired outcomes. Therefore, selfefficacy followed by outcome expectation is progressive antecedents to motivational behaviors. In terms of work, employees with a high degree of self-efficacy expect to find healthy ways to respond to challenges in the work environment.

To sum, there are several models and perspectives for each of our main dimensions, with overlap and lack of clarity seen throughout the development stages as models and theories grow from earlier versions. Moreover, confusion is not limited to our triumvirate.

\section{FURTHER LACK OF CLARITY AMONG THE FACETS}

There is further overlap among various facets or commonalities of our three major constructs. These may appear as the same or similar construct, with an alternate name used by different researchers; or simply as partial crossover with another construct because boundaries and limitations have not been set. One example of this crossover includes the mixture of self-efficacy/self-control/self-regulation. Each has been researched as an individual factor, but the definitions vary and are difficult to separate entirely. Another example involves mastery - this appears in the literature as mastery experiences, mastery goals, and sense of mastery, or mastery of the environment. We will look firstly at self-efficacy.

\subsection{Self-efficacy, Self-control and Self-regulation}

The theme of self-efficacy has occurred repeatedly in all three bodies of literature: in resilience $[4,20,57]$; in engagement $[15,42,58]$; and in motivation $[4,8,50]$. A recent trend in research has focused on self-regulation $[59,60]$ rather than self-efficacy-although self-control has, at some stage, been used to define each construct. According to Gailliot, et al. [61], "Self-regulation (or self-control) is the capacity to override one's thoughts, feelings, and habitual patterns of behavior." For self-efficacy, in his seminal work Bandura [4] referred to the control and regulation of emotion, particularly negative emotions such as anxiety, pessimism, and despair. Latterly, many researchers have expanded the original concept of self-efficacy to focus more on self-confidence rather than the control aspect, and they have added positive coping skills. An updated version now seems to include not only the control of negative emotions but increased emphasis on the ability to envisage a more positive outcome and to create alternative, positive actions which may improve challenging or adversely 
impacted situations. This psychological re-framing is important in a world where change is rapid and adaptability paramount. If taken to extreme, however, self-efficacy may slip into narcissism and unrealistic expectations [62]. Realistic awareness of one's ability to reframe, however, adds to selfconfidence, another element of self-efficacy, and promotes other coping skills.

Further elements linked to self-efficacy, such as selfregulation, have also been explored and have been found to affect both resilience [60] and motivation [5]. Miele and Scholer [5, 63] revisited Maslow's [64] concept of metamotivation-the way that motivation is supported by selfregulation, which combines self-monitoring and self-control. Self-regulation may include moderation of attention, cognition, emotions, and behavior, and some [61] would equate self-regulation with self-control. On the other hand, Fujita [65] argued that self-control is more than simply the "effortful inhibition of impulses", considering it a balance between the value of salient, immediate goals and more abstract future targets. Hence, we have further debate with overlap among the control or regulation facets. Unfortunately, the same applies to those concerned with "mastery".

\subsection{Aspects Pertaining to Mastery}

Similarly, aspects pertaining to mastery, either as "sense of mastery" or "environmental mastery", appear in resilience in a variety of research contexts: 1) in healthcare [66]; 2) in child development, for example in the Resiliency Scale for Children and Adolescents; and 3) in many studies in gerontology [67]. Whereas Schaufeli and Salanova, [68] link "mastery experiences" to motivation [69], and "mastery goals" are evident in studies on motivation and engagement within education [70]. This is especially so in pedagogy [71]. It seems to us that these "mastery goals" in an educational setting compare with "learning goals" and a "learning goal orientation", from an employment context. Perhaps the terms are synonymous and apply within their separate fields. After all, within the education setting the term "learning goal" already existed as the overall outcome for a lesson from the teacher's point of view, at a time when the performance versus learning orientation was first proposed in the world of work. It seems that both terms refer to the process of gradual learning and understanding, (which may include accepting failures along the way) and hence achieving eventually, rather than an immediate performance goal with instant feedback. A further conceptual expression describing a longer term, overarching goal with intermediate failures being accepted is "growth mindset" [72].

To sum, there is both overlay and crossover among several aspects of the three main dimensions, as well as a variety of models and theories which have been developed during the research on each of our triumvirate. However, we posit that the three main constructs are both distinct and interlinked with commonalities and shared antecedents such as self-efficacy.

\subsection{Overlaps and Interconnections among REM Dimensions}

We now consider the evidence that main dimensions are linked. Motivation has always been a requirement for engagement [2, 3, 51, 73, 74]. Moreover, Bakker, et al. [42] concluded in their position paper that resilience was one of the personal resources that may facilitate engagement, citing an earlier study by Bakker, et al. The latter researchers considered the level of engagement among school principals and found that resilience was one of the main factors which explained the variance in these levels. This idea of resilience being linked to the personal resources that contribute to engagement is touched on by Hobfoll, et al. [41] and describe personal resources as "positive self-evaluations found in resiliency, which provide the individuals' sense of agency". While we would agree that positive self-evaluations found in resiliency do indeed provide the individual's sense of agency, we would suggest that other personal resources contribute alongside such self-evaluations to increase resilience and therefore potentially increase engagement, as described above. Consequently:

Proposition 4: Everyday resilience is an antecedent for engagement, at least if that engagement is robust enough to be observed.

In short, there appear to be historic and recently confirmed interdependencies among the main dimensions, in whole or in part as with self-efficacy and self-regulation. We turn now to look in more detail at such interactions among our triumvirate, and the overlap of their facets or commonalities.

\section{FACETS OF RESILIENCE}

Resilience is a newer concept and as such has been investigated less. We would prefer to add a measure of optimism under the umbrella of resilience as suggested by Reivich and Shatte [75]. Surely resilience must include some optimism, or there would be no expectation of success (as required by Vroom's Expectancy Theory [45]; Bandura's Social Learning Theory [6]).Without such expectation there would be no classic "bounce back" as defined by Luthans, et al. [15], just blind, plodding perseverance on what is believed to be an impossible task. Our definition of resilience is thus broader than the latter researchers used in PsyCap, where optimism and hope are separate constructs from resilience [15]. We also differ from the PsyCap model in our view regarding optimism, hope, and goals. Whereas Luthans, et al. [15] took Snyder's [16] definition of "hope" from clinical psychiatry where it was used with reference to major trauma, we prefer a more everyday definition for our more everyday context. To us, hope can provide the inspiration for motivation, which will thus have the "meaningful" aspect required in both Hackman and Oldham's job design model and Kahn's [2] definition of engagement. In our view, the locus of control for hope may be largely external. We suggest that a personal goal must involve mainly internal locus of control or agency, in order to produce both purpose and determination; and for a goal to be realistic, a realistic level of optimism about its achievability is needed among the aspects of 
resilience. To sum, in our opinion, hope is linked more to motivation than to everyday resilience. Self-efficacy and optimism are linked with resilience, but as facets under the umbrella of resilience, rather than as stand-alone factors in PsyCap.

As we have seen, there are differences of opinion regarding the definitions of many constructs. On the other hand, there are some generally agreed components from measurements such as the Connor-Davidson Resilience Scale [22] and others. Of these factors listed by Rees, et al. [20], we would group together some of the components, to provide the constructs of realistic optimism mentioned above, and accumulated selfefficacy, both of which appear in our REM model. The other listed components are control and hardiness. We would assume these to include determination, persistence, and selfcontrol; together these will likely make up the construct of self-regulation (which has received much attention in recent years). The components from the meta-analysis mentioned by Rees, et al. [20] would be combined into groups as follows:

- Acceptance of change, problem-solving, creativity, insight, independence-all these are required in some measure (with huge variation across individual personalities) for realistic optimism and psychological reframing of adversity (e.g., "I can find a way around this").

- Self-esteem, personal competence, initiative (here we would add "mastery experiences") - these make up the background or accumulated level of self-efficacy, sometimes with personal competence used as the umbrella term (e.g., "I'm worth it, and I'm going to do it").

- Control and hardiness - these make up the self-regulation element (e.g., "I can survive, I can get by and stay on track").

- Social competence, social resources (at home and at work), and family cohesion provide a supportive social context, with personal additions of humor and spiritual influences - not necessarily religious, just a link to something bigger than self (e.g., "I'm not in this alone, I can get help").

All the above factors (apart from mastery experiences) were extracted and collected by meta-analysis of several measures of resilience, by Windle, et al. [21] who attempted to find a "gold standard" instrument to recommend. From this we propose the following:

Proposition 5: We re-group the most commonly accepted cooccurring components of resilience into realistic optimism, personal competence (from accumulated self-efficacy), selfregulation, and a supportive social context.

For our grouping above, we have already alluded to the presence of self-efficacy in earlier research. Recent academic interest in the topic of self-regulation is linked to both resilience and motivation, and to the need for social resources and personal resources at work. We now consider how realistic optimism may be produced or increased.

A second stream of research from Seligman [76] suggested that optimism can be learned from a series of positive achievements, just as his earlier works [77] suggested that repeated negative consequences can produce what he termed "learned helplessness". We suggest that learned optimism is what feeds into self-efficacy over time. Reivich and Shatte [75] contrasted this more realistic optimism learned as a result of repeated successes, with that of the "Pollyanna" disposition sometimes seen, where the level of optimism tips over into unrealistic attributions and expectations. Schaufeli and Salanova [68] and Pink [69], asserted that mastery experiences (c.f. [75], repeated successes) were both the result and the antecedent of engagement. Occasionally, learned optimismwithout objective self-monitoring - sets in, and a lack of selfcontrol allows impulsive behavior. Such instances are seen among entrepreneurs, for example, [78, 79] and illustrate an imbalance among the facets of resilience.

Having broken down and re-grouped the various intrapersonal aspects of resilience - into realistic (learned) optimism, selfregulation, and accumulated self-efficacy-we situate these within the interpersonal context of social support at work and at home. We turn now to the second of the three main constructs in our model, engagement.

\section{FACETS OF ENGAGEMENT}

Engagement has had many definitions. The one we prefer is frequently used in research today [43] and has three dimensions of dedication, vigor, and absorption. Schaufeli, et al. [35] linked their definition back to Kahn's [2] original concept as a positive, fulfilling, work-related state of mind. They further explained the antecedents for dedication as inspiration and challenge, which then resulted in immersion in the task. Vigor or energy, as the behavioral element of engagement, is the most visible, measurable facet for observers, with positive affect also being apparent. According to Schaufeli, et al. [35], absorption requires an overwhelming interest in the subject. On occasion this may be only momentary. However, for engagement in the task to be maintained, the absorption must continue to the completion of the task. We agree that engagement is task dependent. Hence an employee whose job involves many motivating and engaging tasks may love their job, be inspired by their manager, and be committed to their organization; but the element of absorption will generally be shown only in individual tasks. If absorption with the job does occur, perhaps it demonstrates the obsessive nature of workaholism rather than the positive affect and inspired absorption seen in engagement [80, 81].

It is our belief that all three facets must be created and sustained by a combination of motivation and resilience; and that this must occur within a supportive context, at work (in terms of job resources leading to job satisfaction) and 
elsewhere, to enable the personal resources of Kahn's "availability". Consequently:

Proposition 6: Adequate job satisfaction is an antecedent to personal availability, which is an antecedent to engagement at work.

We now consider how motivation and resilience may combine to produce intrapersonal engagement in a suitable task, first looking at intrinsic motivation.

\section{HOW INTRINSIC MOTIVATION CREATES ENGAGEMENT}

As discussed above, our preferred definition of engagement has three facets, the more widely agreed factors being dedication and vigor. We will look firstly at the way in which motivation is needed to create engagement, before considering how resilience supports and sustains it. Engagement is illustrated by the shaded ovoid in the diagram below, and our first facet of engagement is dedication, which is the left sphere inside the ovoid (Figure 1).

\subsection{Dedication}

For someone to be dedicated to a task they must be motivated by the process itself (intrinsic motivation). The antecedents for this are inspiration, which provides task meaningfulness, and challenge which invokes the self-efficacy of the person. Thus, once the task is both meaningful and challenging, the person will be proud to bring their "best or preferred self", resulting in immersion in the task. As a side note, if a meaningful task is not sufficiently challenging, then some individuals will set their own goal or deadline in order to increase the difficulty to the level required for their task self-efficacy to be brought into play. This is an example of meta-motivation, the regulation of one's own motivational state $[5,51,63,64,73,74,82]$. It also illustrates another factor found to increase engagement, that of job-crafting [51, 73, 74]; Gordon, et al. [83]; Tims, et al. [84]. (For the sake of clarity, this feedback loop is not shown on the diagram as it applies only in specific cases). Hence the task is (or has been made) sufficiently challenging, and at this point there is both affective and cognitive alignment with the task and immersion is achieved, producing increased effort observed as vigor.

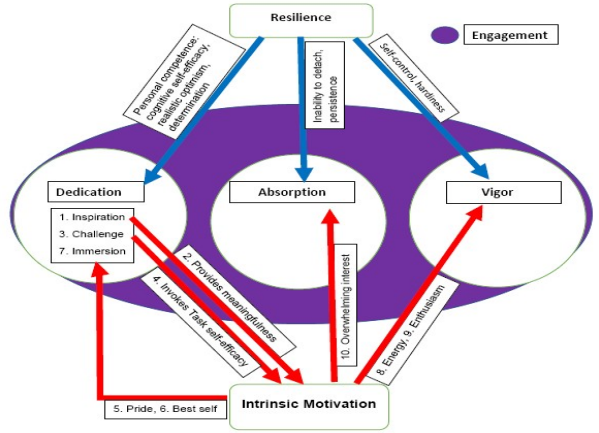

Figure 1: How motivation interacts with the engagement factors of dedication, vigor and absorption, and resilience then supports each factor.
Firstly, inspiration provides meaningfulness, then challenge invokes task self-efficacy. Together these create intrinsic motivation which awakens pride and best self, (resulting in immersion) and generates energy and enthusiasm (vigor). Absorption follows.

\subsection{Vigor}

The second main factor is the energetic or physical component, named "vigor" by Schaufeli, et al. [35]. For this to be demonstrated, there must be energy, provided by the motivation and enthusiasm to take on the task; and that energy must be sustained, through a mindset of "I can cope, I will see this through". Again, this physical persistence is maintained by the effects of accumulated self-efficacy from the resilience, the physical self-control. It seems reasonable that there should be an accumulated effect of self-efficacy over successes in multiple tasks, and that this should increase with age and experience to give an awareness of one's own endurance capabilities; but maybe "personal competence" or "previous mastery experience" describes the concept better than "accumulated self-efficacy".

\subsection{Absorption}

Finally, the individual becomes absorbed in the task. This is the third factor of engagement, which is demonstrated by overwhelming interest and cognitive focus. This interest may be momentary unless combined with persistence to illustrate an inability to detach from the task or pastime for distractions such as phone calls. If Csikszentmihalyi's [85] ultimate state of "flow" is reached, one may even refuse to stop and eat! Perhaps this is the behavior noted by Loscalzo and Giannini [86] in their review as "work-devoted" or "engaged workaholics".

\section{\% 9. HOW RESILIENCE SUSTAINS ENGAGEMENT}

We now investigate how this level of engagement can be maintained in the face of obstacles or setbacks. As previously stated, Bakker, et al. [42] found that engaged employees were generally resilient. Engagement increases with the level of interest in the task at hand. An employee who is immersed in the job will be temporarily engaged; but will require resilience to hold that level if obstacles are to be overcome. Such an increase in job demands will require extra input in the form of personal resources, or job resources (JD-R theory). The main personal resource required is resilience. Facets of resilience will each bolster different aspects of engagement. Psychological reframing and realistic optimism will see a way around or past the problem to re-inspire and overcome the challenge, and determination will maintain that dedication in the face of an increased level of challenge; self-control and hardiness will keep the required level of vigor. Otherwise, extra job resources such as more help or support will be required to maintain the level of engagement and prevent the employee from feeling overwhelmed.

Here we propose that resilience also encompasses the accumulated self-efficacy, which bolsters both optimism and 
determination. Imperatori [37] postulated that there is a feedback loop running "back from performance and engagement to job and personal resources due to resource accumulation following successful performance" (suggesting the review by Salanova, et al. [87]). Hence, increases in work engagement can lead to increases in resources, as well as the expected reciprocal arrangement. We would describe this development of personal resources as an increase in selfefficacy. Each successful performance will increase selfefficacy, in terms of both the momentary or state self-efficacy of the task (the new knowledge) and of the accumulated selfefficacy, self-esteem and personal competence, found in resilience.

The move from attempt into mastery will increase self-esteem, decrease stress levels, creating positive affect. Hence, the accumulated self-efficacy or mastery experience will be marginally improved with each successful episode, and the positive affect will prime the individual to accept similar challenges in future. Further, if the job resources were adequate on this occasion, when these high job demands were made, then that suggests those same resources, will again be sufficient in the future. It seems likely that trust in these resources, and thus the perceived social context at work, is improved as a result of any initial success. Moreover, future motivation to take on similar or more difficult challenges will also be increased, encouraging further engagement later, so long as the job characteristics are maintained [51, 73, 74]. Perhaps these are the underlying aspects of Pink's [69] contention that mastery leads to more mastery, as both the result and the future antecedent of engagement. This result, this mastery experience, becomes part of resilience, increasing the accumulated self-efficacy. As already mentioned, selfefficacy is an accepted antecedent for resilience [4, 20, 57]. Thus:

Proposition 7: To a degree, successful performances or mastery experiences are antecedents to accumulated selfefficacy, adding to the overall personal competence and raising the level of realistic optimism.

Having considered the way that intrinsic motivation feeds into engagement, we now consider the extrinsic or controlling forms of motivation. Job resources [1], Herzberg's [47] hygiene factors, and Hackman \& Oldham's job design [51, 73, 74] are enough to maintain job satisfaction so that employees are retained in post. These job-related factors are enough to encourage employees to work reasonably hard in the hope of a pay raise, promotion, or job security, etc. Moreover, an adequate level of job satisfaction as a baseline is generally required before engagement can happen. However, these factors are insufficient to promote dedication or absorption. For this to occur, the task must have pertinence to the employee: It must be meaningful to provide the "inspired" aspect, and it must be at a challenging level - either in terms of difficulty or as an easier task with a tight deadline. These factors are both necessary to awaken the pride and Kahn's [2] "best self" of intrinsic motivation to produce the immersion required and fully show the dedication factor. But we must also consider what will happen if there is a major extrinsic motivator, such as the promise of promotion, or large commission on a sale; whether this will increase the level of dedication and result in greater engagement.

\section{THE EFFECT OF EXTRINSIC MOTIVATION ON ENGAGEMENT}

For some people, external reward will be enough to motivate them, but the task itself will not have personal meaningfulness for them; thus, their engagement with the task will be limited because their focus will be on their reward. This external focus means that they will maintain control, rather than surrendering themselves to the task. They will not be absorbed by the work, hence could not attain "flow" because their interest in the process is far from overwhelming. They may attack the task with vigor, being challenged and apparently single-minded, but in fact their goal includes more than completion of the task; this is just an intermediate step on that individual's' trajectory toward their personal goal. For others who already had autonomous motivation toward a project, extra pecuniary reward is unlikely to aid engagement further. As we have already seen [53-55] an increase in extrinsic reward can take the joy out of the task, turn it into a controlled chore, and decrease the net motivation. If additional extrinsic motivation does not increase task engagement, we need to consider what will do so.

\section{: 11. HOW TO INCREASE ENGAGEMENT}

If intrinsic motivation is already present in a context with job satisfaction, then building up self-efficacy or social support at work in order to promote resilience is likely to be much more effective than a pecuniary reward. The former intervention may lead to higher levels of engagement through any adversity encountered and will also tend to avoid burnout. That secondary aspect of supportive context is the background setting for resilience: It is generally a required antecedent, allowing engagement to happen if the other factors are in place. It is not illustrated in the function of the model, as that is task specific. However, each employee interacts as part of a team or group. So, for resilience in the workplace, the social context at work is important as one of the job resources. Without social context, employees will feel isolated and will have limited resilience in times of adversity. They may never reach the threshold of task engagement unless their intrinsic motivation for a task is particularly high and there are no immediate challenges. Hence, to enable engagement, there is a need to improve the social context at work. To aid engagement at work, the most important relationship is the dyad between manager and employee [88]. Hence,

Proposition 8: Leadership that includes coaching, mentoring, or improving the culture of a work team is an antecedent to engagement. 


\section{Business and Management Research (IJBMR)}

Review Article | Volume 9, Issue 2 | Pages 178-189 | e-ISSN: 2347-4696

\section{CONCLUSION}

From the comprehensive review and integration of the literature surrounding resilience, engagement, and motivation, we drew eight propositions including the definition of engagement from Schaufeli, et al. [35]. Investigating each of our three concepts, we found connections and co-occurring factors among the main REM dimensions. Thus, we created an integrated model suggesting how all these constructs work together. In future research, we hope to provide prescriptive antecedent suggestions for managers to optimize the work environment so that REM may flourish at the intrapersonal level for their employees and themselves. The order in which antecedents are addressed may prove to be important, if (as we surmise) engagement generally becomes possible only once job satisfaction and perceived job resources are at an adequate level for the individual. Then, and only then, may personal resources allow for Kahn's "preferred self" to be motivated by an inspiring and challenging task [2]. Furthermore, personal resilience must be, and must remain, at an adequate level for engagement to be sustained through obstacles and adversity.

Although our theorizing integrates many viewpoints and much of the literature surrounding resilience, engagement, and motivation, further research is required to test this holistic framework. While the model offers a comprehensive perspective at the intrapersonal level, testing of the eight propositions and application will confirm the model's usefulness. For example, are the three REM variables distinct, complementary, interactive, and coherent? In some particular order, do they produce a synergistic effect? Are they generalizable across environments?

We recommend testing the REM model empirically and practically such that both scholars and practitioners gain insight for future research and application. We assert that the integration of the resilience, engagement, and motivation (REM) model tenets first offers the power to analyze and explain the current state of an organization's social context. Second, we believe that well-designed research of the model has the ability to test the eight propositions recommended in this writing. We believe that the model can help design and predict the outcome of planned intervention outcomes such as, for example, Proposition 8, ensuring "leadership that includes coaching, mentoring, or improving the culture of a work team is an antecedent to engagement." To what extent does such leadership produce REM? Third, we assert the REM model has the potential to be useful in the redesign of a robust organizational social context for individuals.

Therefore, with regard to potential research methods, we recommend organization field studies in various sector environments, e.g., education, government, business, industry, and non-profit to determine generalizability of the model. Research could be conducted in a naturalistic setting with bona fide groups of individuals, i.e., employees, engaged in the context of their work environment. Each of the eight propositions can be systematically tested by, for example, introducing related human resource and structural interventions in the design of a quasi-experiment. For applied quantitative research, we do recommend a quasi-experimental non-equivalent control group design including a pre-test and repeated measure post-test survey with a control group [86] measuring job satisfaction, resources, resilience, engagement, and motivation. In between repeated measures, organizations may use the model to custom-design and introduce interventions such as structural or reward changes, specialized training for leaders and followers, job design, resource allocation, and the like. Correlating the eight proposition outcomes with these variables is essential and requires careful experimental design.

With regard to qualitative research, mixed methods to achieve triangulation may include leader/follower interviews, focus groups, and ethnographic observations, e.g., participantobservers describing, for example, observed REM behavior in meetings, the office, and water cooler. Interviews with randomly selected participants may fill in the blanks created by the quantitative research method suggested.

Finally, there are some issues that may arise in choosing REM operational definitions and from them, the testing of the model. As noted above, determining the order of, and measuring the degree of interaction effects between, variables toward desired outcomes is complicated, even messy. Attempt to employ graphic models to capture both the distinctiveness and complementarity of variables is also challenging. Again, qualitative methods may offset gaps in imperfect quasiexperimental designs.

\section{REFERENCES}

[1] Bakker, A., \& Demerouti, E. (2007) The Job DemandsResources model: State of the art. Journal of Managerial Psychology, 22: 309-328.

[2] Kahn, W. A. (1990) Psychological Conditions of Personal Engagement and Disengagement at work. The Academy of Management Journal, 33(4): 692-724.

[3] Delaney, M. L. \& Royal, M. A. (2017) Breaking Engagement Apart: The Role of Intrinsic and Extrinsic Motivation in Engagement Strategies. Industrial and Organizational Psychology, 10(1): 127-140.

[4] Bandura, A. (1997) Self-efficacy: The exercise of control. Stanford, USA : W.H. Freeman.

[5] Miele, D. B., \& Scholer, A. A. (2016) Self-regulation of Motivation. In: Wentzl, K. R., Miele, D. B. (Eds.), Handbook of Motivation at School. (pp. 363-384). New York, USA: Routledge.

[6] Bandura, A. (1971) Psychological modeling; conflicting theories. Chicago, USA: Aldine-Atherton.

[7] Bandura, A. (2012) On the functional properties of perceived self-efficacy revisited. Journal of Management, 38(1): 9-44.

[8] Bandura, A. (2015). On Deconstructing Commentaries Regarding Alternative Theories of Self-Regulation. Journal of Management, 41(4): 1025-1044.

[9] Vancouver, J., \& Kendall, L. (2006) When Self-Efficacy Negatively Relates to Motivation and Performance in a Learning Context. Journal of Applied Psychology, 91(5): 1146-1153. 


\section{Business and Management Research (IJBMR)}

Review Article | Volume 9, Issue 2 | Pages 178-189 | e-ISSN: 2347-4696

[10] Vancouver, J., \& Purl, J. (2017) A Computational Model of Self-Efficacy's Various Effects on Performance: Moving the Debate Forward. Journal of Applied Psychology, 102(4): 599616.

[11] Kobasa, S. (1979) Stressful life events, personality, and health: An inquiry into hardiness. Journal of Personality and Social Psychology, 37(1): 1-11.

[12] Rutter, M. (1985) Resilience in the face of adversity. Protective factors and resistance to psychiatric disorder. The British Journal of Psychiatry: The Journal of Mental Science, 147: 598-611.

[13] Rodríguez-Rey, R., Palacios, A., Alonso-Tapia, J., Pérez, E., Álvarez, E., et al. (2017) Posttraumatic growth in pediatric intensive care personnel: Dependence on resilience and coping strategies. Psychological Trauma: Theory, Research, Practice, and Policy, 9(4): 407-415.

[14] Walsh, D. M. J., Morrison, T. G., Conway, R. J., Rogers, E., Sullivan, F. J., et al. (2018) A model to predict psychologicaland health-related adjustment in men with prostate cancer: The role of post traumatic growth, physical post traumatic growth, resilience and mindfulness. Frontiers in Psychology, 9: 12.

[15] Luthans, F., Youssef, C., \& Avolio, B. (2007) Psychological Capital: Developing the Human Competitive Edge. New York, USA: Oxford University Press.

[16] Snyder, C., Feldman, D., Taylor, J., Schroeder, L., \& Adams, V. (2000) The roles of hopeful thinking in preventing problems and enhancing strengths. Applied and Preventive Psychology, 9(4): 249-269.

[17] Seligman, M. (2017) Building Resilience. In: M. Seligman, T. Schwartz, W. Bennis, and R. Thomas, (Eds.), On Mental Toughness, (pp. 25-26). Boston, MA, USA: Harvard Business Review Press.

[18] Peterson, C., Park, N., \& Castro, C. A. (2011) Assessment for the U.S. army comprehensive soldier fitness program: The global assessment tool. American Psychologist, 66(1): 10-18.

[19] Cornum, R., Matthews, M. D., \& Seligman, M. E. P. (2011) Comprehensive soldier fitness: Building resilience in a challenging institutional context. American Psychologist, 66(1): 4-9.

[20] Rees, C.S., Breen, L.J., Cusack, L., \& Hegney, D. (2015) Understanding individual resilience in the workplace: The international collaboration of workforce resilience model. Frontiers of Psychology, 6: 73.

[21] Windle, G., Bennett, K. M., \& Noyes, J. (2011) A methodological review of resilience measurement scales. Health Quality of Life Outcomes, 9: 8.

[22] Connor, K. M., \& Davidson, J. R. T. (2003) Development of a new resilience scale: The Connor-Davidson Resilience Scale (CD-RISC). Depression \& Anxiety, 18: 71-82.

[23] McLarnon, M. J. W. \& Rothstein, M. G. (2013) The Development and Validation of the Workplace Resilience Inventory. Journal of Personnel Psychology, 12(2): 63-73.

[24] Geers, A. L., Wellman, J. A., \& Lassiter, G. D. (2009) Dispositional optimism and engagement: The moderating influence of goal prioritization. Journal of Personality and Social Psychology, 96(4): 913-932.

[25] Happer, K., Brown, E. J., \& Sharma-Patel, K. (2017) Children's resilience and trauma-specific cognitive behavioral therapy: Comparing resilience as an outcome, a trait, and a process. Child Abuse \& Neglect, 73: 30 .
[26] Garcia-Dia, M. J., DiNapoli, J. M., Garcia-Ona, L., Jakubowski, R., \& O'Flaherty, D. (2013) Concept analysis: resilience. Psychiatric Nursing, 27: 264-270.

[27] Shuck, B., \& Wollard, K. (2010) Employee Engagement and HRD: A Seminal Review of the Foundations. Human Resource Development Review, 9(1): 89-110.

[28] Shuck, B. (2011) Four emerging perspectives of employee engagement: an integrative literature review. Human Resource Development Review, 10 (3): 304-328.

[29] Maslach, C., \& Jackson, S. (1981) The measurement of experienced burnout. Journal of Occupational Behavior (pre1986), 2(2): 99-113

[30] Harter, J., Schmidt, F., \& Hayes, T. (2002) Business-Unit-Level Relationship Between Employee Satisfaction, Employee Engagement, and Business Outcomes: A Meta-Analysis. Journal of Applied Psychology, 87(2): 268-279.

[31] Saks, A. (2006) Antecedents and consequences of employee engagement. Journal of Managerial Psychology, 21(7): 600-619.

[32] Simpson, M. (2009) Engagement at Work: A review of the literature. International Journal of Nursing Studies. 46: 1012 1024.

[33] Knight, C., Patterson, M., \& Dawson, J. (2017) Building work engagement: A systematic review and meta-analysis investigating the effectiveness of work engagement interventions. Journal of Organizational Behavior, 38(6): 792812

[34] Maslach, C., \& Leiter, M. P. (1997) The Truth about Burnout: How Organizations Cause Personal Stress and What to Do about It. San Francisco, CA, USA: Jossey-Bass.

[35] Schaufeli, W. B., Salanova, M., Gonzalez-Roma, V., \& Bakker, A. B. (2002) The measurement of engagement and burnout: A two-sample confirmatory factor analytic approach. Journal of Happiness Studies, 3(1): 71-92.

[36] Cole, M. S., Walter, F., Bedeian, A. G., \& O’Boyle, E. H. (2012) Job burnout and employee engagement a meta-analytic examination of construct proliferation. Journal of Management, 38(5): 1550-1581.

[37] Imperatori, B. (2017) Engagement and disengagement at work: Drivers and organizational practices to sustain employee passion and performance New York, NY, USA: Springer Science \& Business Media.

[38] Schaufeli, W. B. \& Bakker, A. B. (2004) Job demands, job resources, and the relationship with burnout and engagement: A multi-sample study. Journal of Organizational Behavior, 25: 293-315.

[39] Xanthopoulou, D., Bakker, A. B., Demerouti, E., \& Schaufeli, W. B. (2009) Reciprocal relationships between job resources, personal resources, and work engagement. Journal of Vocational Behavior, 74(3): 235-244.

[40] Kim, W., Kolb, J., \& Kim, T. (2013) The relationship between work engagement and performance: A review of empirical literature and a proposed research agenda. Human Resource Development Review, 12(3): 248-276.

[41] Hobfoll, S. E., Johnson, R. J., Ennis, N., \& Jackson, A. P. (2003) Resource loss, resource gain, and emotional outcomes among inner city women. Journal of Personality and Social Psychology, 84(3): 632-643. 


\section{Business and Management Research (IJBMR)}

Review Article | Volume 9, Issue 2 | Pages 178-189 | e-ISSN: 2347-4696

[42] Bakker, A., Schaufeli, W., Leiter, M., \& Taris, T. (2008) Work engagement: An emerging concept in occupational health psychology. Work \& Stress, 22(3): 187-200.

[43] Bakker, A., \& Albrecht, S. (2018) Work engagement: current trends. Career Development International, 23(1): 4-11.

[44] Sonnentag, S., Dormann, C. and Demerouti, E. (2010) "Not all days are created equal: The concept of state work engagement". In: A.B. Bakker \& M.P. Leiter, (Eds.), Work Engagement: A Handbook of Essential Theory and Research, pp. 25-38. Hove, Sussex: Psychology Press.

[45] Vroom, V. H. (1964) Work and Motivation. New York, USA: Wiley.

[46] Vroom, V. H. (1995) Work and Motivation (revised edition). San Francisco, CA, USA: Jossey-Bass.

[47] Herzberg, F., Mausner, B., \& Snyderman, B. (1959) The Motivation to Work. New York, USA: John Wiley.

[48] Herzberg, F. (1987) One more time: how do you motivate employees? (HBR Classic). Harvard Business Review, 65.

[49] Locke, E., \& Latham, G. (1990) A theory of goal setting and task performance. Englewood Cliffs, NJ, USA: Prentice Hall.

[50] Locke, E., \& Latham, G. (2006) New directions in goal-setting theory. Current Directions in Psychological Science, 15: 265268.

[51] Hackman, J., Oldham, G., \& Feishman, E. (1975) Development of the Job Diagnostic Survey. Journal of Applied Psychology, 60(2): 159-170.

[52] Koch, S. (1955) Behavior as "intrinsically" regulated: Work notes towards a pre-theory of phenomena called "Motivational.". In: M. R. Jones (Ed.), Nebraska symposium on motivation:1955 (pp. 42-87) University of Nebraska Press, Lincoln, NE.

[53] Lepper, M. R., \& Greene, D. (1975) Turning play into work: Effects of adult surveillance and extrinsic rewards on children's intrinsic motivation. Journal of Personality and Social Psychology, 31(3): 479-486.

[54] Lepper, M. R., Greene, D., \& Nisbett, R. E. (1973) Undermining children's intrinsic interest with extrinsic reward: A test of the "over-justification" hypothesis. Journal of Personality and Social Psychology, 28(1): 129-137.

[55] Deci, E., \& Lanzetta, J. (1971) Effects of externally mediated rewards on intrinsic motivation. Journal of Personality and Social Psychology, 18(1): 105-115.

[56] Deci, E., Koestner, R., \& Ryan, R. (1999) A Meta-Analytic Review of Experiments Examining the Effects of Extrinsic Rewards on Intrinsic Motivation. Psychological Bulletin, 125(6): 627-668.

[57] Rutter, M. (2012) Resilience as a dynamic concept. Development and Psychopathology, 24(2): 335-344.

[58] Salanova, M., Llorens, S., \& Schaufeli, W. (2011) "Yes, I can, I feel good, and I just do it!" On gain cycles and spirals of efficacy beliefs, affect, and engagement. Applied PsychologyAn International Review-Psychologie Appliquee-Revue Internationale, 60(2): 255-285.

[59] O'Shea, D., Buckley, F., \& Halbesleben, J. (2017) Selfregulation in entrepreneurs: Integrating action, cognition, motivation, and emotions. Organizational Psychology Review, 7(3): 250-278.

[60] Rothstein, M. G., McLarnon, M.J.W., \& King, G. A. (2016) The Role of Self-Regulation in Workplace Resiliency. Industrial and
Organizational Psychology: Perspectives on Science and Practice, 9: 416-421.

[61] Gailliot, M. T., Schmeichel, B. J., \& Baumeister, R. F. (2006) Self-regulatory processes defend against the threat of death: Effects of self-control depletion and trait self-control on thoughts and fears of dying. Journal of Personality and Social Psychology, 91(1): 49-62.

[62] Beattie, S., Dempsey, C., Roberts, R., Woodman, T., \& Cooke, A. (2017) The moderating role of narcissism on the reciprocal relationship between self-efficacy and performance. Sport, Exercise, and Performance Psychology, 6(2): 199-214.

[63] Miele, D. B., \& Scholer, A. A. (2018) The role of metamotivational monitoring in motivation regulation. Educational Psychologist, 53: 1-21.

[64] Maslow, A. (1967) A Theory of Metamotivation: The Biological Rooting of the Value-Life. Journal of Humanistic Psychology, 7(2): 93-127.

[65] Fujita, K. (2011) On conceptualizing self-control as more than the effortful inhibition of impulses. Personality and Social Psychology Review, 15(4): 352-366.

[66] Gallagher, M. W., Long, L. J., Richardson, A., \& D'Souza, J. M. (2019) Resilience and coping in cancer survivors: The unique effects of optimism and mastery. Cognitive Therapy and Research, 43(1): 32-44.

[67] Montpetit, M. A., \& Tiberio, S. S. (2016) Probing resilience: Daily environmental mastery, self-esteem, and stress appraisal. The International Journal of Aging \& Human Development, 83(4): 311-332.

[68] Schaufeli, W. B., \& Salanova, M. (2010) How to improve work engagement? In: S. L. Albrecht (Ed.), Handbook of employee engagement: Perspectives, issues, research and practice; handbook of employee engagement: Perspectives, issues, research and practice (pp. 399-415). Northampton, MA, USA Edward Elgar Publishing.

[69] Pink, D. H. (2009) Drive. New York, USA: Riverhead.

[70] Clarke, R.C. (2016) Building Expertise: cognitive methods for training and performance improvement. San Francisco, USA: Wiley.

[71] Schweder, S. (2019) Mastery goals, positive emotions and learning behavior in self-directed vs. teacher-directed learning. European Journal of Psychology of Education, 35: 205-223.

[72] Dweck, C. (2008) Mindset: The new psychology of success. New York, USA: Ballantine Books.

[73] Hackman, J. R., \& Oldham, G. R. (1976) Motivation through the design of work: Test of a theory. Organizational Behavior and Human Performance, 16: 250-279.

[74] Hackman, J. R., \& Oldham, G. R. (1980) Work redesign. Reading, MA, USA: Addison-Wesley.

[75] Reivich, K., \& Shatte, A. (2002) The Resilience Factor. New York, USA: Crown Publishing Group.

[76] Seligman, M. (1990). Learned optimism. New York, USA: A.A. Knopf.

[77] Seligman, M. E. (1972) Learned helplessness. Annual Review of Medicine, 23: 407-412.

[78] Baron, R. A., Mueller, B. A., \& Wolfe, M. T. (2016) Selfefficacy and entrepreneurs' adoption of unattainable goals: The restraining effects of self-control. Journal of Business Venturing, 31(1): 55-71. 
[79] Vancouver, J., Thompson, C., \& Williams, A. (2001) The Changing Signs in the Relationships Among Self-Efficacy, Personal Goals, and Performance. Journal of Applied Psychology, 86(4): 605-620.

[80] Hakanen, J. J., Schaufeli, W. B. \& Ahola, K. (2008) The job demands-resources model: A three-year cross-lagged study of burnout, depression, commitment, and work engagement. Work \& Stress: An International Journal of Work, Health \& Organisations, 22(3): 224-241.

[81] Zeijen, M., Peeters, M., \& Hakanen, J. (2018) Workaholism versus work engagement and job crafting: What is the role of self-management strategies? Human Resource Management Journal, 28(2): 357-373.

[82] Nguyen, T., Carnevale, J., Scholer, A., Miele, D., \& Fujita, K. (2019) Metamotivational Knowledge of the Role of High-Level and Low-Level Construal in Goal-Relevant Task Performance. Journal of Personality and Social Psychology, 117(5): 876-899.

[83] Gordon, H. J., Demerouti, E., Le Blanc, P.M., Bakker, A. B., Bipp, T., et al. (2018) Individual job redesign: Job crafting interventions in healthcare. Journal of Vocational Behavior, 104: 98.

[84] Tims, M., Bakker, A. B., \& Derks, D. (2012) Development and validation of the job crafting scale. Journal of Vocational Behavior, 80(1): 173-186.
[85] Csikszentmihalyi, M. (1990) Flow: The Psychology of Optimal Experience. New York, NY, USA: Harper \& Row.

[86] Loscalzo, Y., \& Giannini, M. (2017) Clinical conceptualizations of workaholism: A comprehensive model. Organizational Psychology Review, 7(4): 306-329.

[87] Salanova, M., Schaufeli, W. B., Xantholpoulou, D., \& Bakker, A. B. (2010) The gain spiral of resources and work engagement: Sustaining a positive work-life. In: A. B. Bakker \& M. P. Leiter, (Eds.) Work Engagement: A Handbook of Essential Theory and Research, (pp. 118-131). New York, NY, USA: Psychology Press.

[88] Tims, M., Bakker, A. B., \& Xanthopoulou, D. (2011) Do transformational leaders enhance their followers daily work engagement? The Leadership Quarterly, 22(1): 121-131.

[89] Frey, L.R., Botan, C.H., Friedman, P.G., \& Kreps, G. (1991) Investigating Communication: An Introduction to Research methods. Englewood Cliffs, NJ, USA: Prentice-Hall.

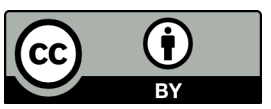

(C) 2021 by the Alison Jolliff and David Strubler. Submitted for possible open access publication under the terms and conditions of the Creative Commons Attribution (CC BY) license (http://creativecommons.org/licenses/by/4.0/). 